\title{
Analysis of creep behavior of SiC/Al metal matrix composites based on a generalized shear-lag model
}

\author{
Ho J. Ryu \\ Dry Process Fuel Technology Division, Korea Atomic Energy Research Institute, \\ Daejeon 305-353, Korea \\ Kyung H. Chung \\ College of Engineering, University of California-Davis, Davis, California 95616 \\ Seung I. Cha and Soon H. Hong ${ }^{\text {a) }}$ \\ Department of Materials Science and Engineering, Korea Advanced Institute of Science and \\ Technology, Daejon 305-701, Korea
}

(Received 22 July 2004; accepted 15 September 2004)

\begin{abstract}
The creep behaviors of $20 \mathrm{vol} \% \mathrm{SiCw} / 2124 \mathrm{Al}$, extruded with different ratios, and $\mathrm{SiCp} / 2124 \mathrm{Al}$, reinforced with $10-30 \mathrm{vol} \% \mathrm{SiC}$ particles, were investigated to clarify the effects of aspect ratio, alignment, and volume fraction of reinforcement on creep deformation. The effective stresses on the matrix of $\mathrm{SiC} / \mathrm{Al}$ composites are calculated based on the generalized shear-lag model. The minimum creep rates of SiCw/2124Al extruded with different ratios and $\mathrm{SiCp} / 2124 \mathrm{Al}$ reinforced with different volume fractions of $\mathrm{SiC}$ particles are found to be similar under a same effective stress on matrix, which is calculated by the generalized shear-lag model. The subgrain sizes in matrices of crept SiC/Al composites are dependent on the effective stress on matrix but not on the applied stress on the composite. It is suggested that the role of $\mathrm{SiC}$ reinforcements is to increase the creep resistance of $\mathrm{SiC} / \mathrm{Al}$ composite by reducing the effective stress on matrix.
\end{abstract}

\section{INTRODUCTION}

Metal matrix composites (MMCs) such as $\mathrm{SiC} / \mathrm{Al}$ composites show improved high-temperature creep resistance compared to their monolithic matrix alloys. ${ }^{1,2}$ This improvement is achieved by an addition of high modulus ceramic reinforcement into a ductile metal matrix having low strength at elevated temperatures. The understanding and prediction of creep behavior of $\mathrm{SiC} / \mathrm{Al}$ composites are highly needed for the structural application at high temperature.

The high-temperature creep behavior of MMCs has been investigated by several researchers. ${ }^{2-16}$ Morimoto et $\mathrm{al}^{2}$ found that the higher volume fraction and the larger aspect ratio of reinforcement resulted in an increased creep resistance of $\mathrm{SiCw} / 2124 \mathrm{Al}$ composite. Nieh et al. ${ }^{3}$ found that the creep behavior of SiC/Al composite shows minimum creep rate without showing welldefined steady-state creep region. It has been found that the creep of $\mathrm{SiC} / \mathrm{Al}$ composite is controlled by the lattice diffusion of $\mathrm{Al}$ in matrix. ${ }^{4,5} \mathrm{An}$ overview of the creep behavior of $\mathrm{SiC} / \mathrm{Al}$ composites shows that the whiskerreinforced composites generally exhibit a higher creep

\footnotetext{
a) Address all correspondence to this author.

e-mail: shhong@kaist.ac.kr

DOI: 10.1557/JMR.2004.0472
}

resistance than the particle reinforced composites, and the stress exponent and activation energy for creep are much higher than those observed for pure aluminum. The higher stress exponent and activation energy for creep have been attributed to the presence of threshold stress. ${ }^{6-8}$ Park et al. ${ }^{10}$ have indicated that the stress exponent and activation energy for creep increase with decreasing the applied stress. Li and Mohamed ${ }^{11}$ showed that the creep behavior of $\mathrm{SiCp} / 2124 \mathrm{Al}$ composite fabricated by the powder metallurgy (PM) process is similar to that of 2124Al alloy fabricated by the PM process. They have suggested that the source of threshold stress could be the oxide particles incorporated during the PM processing. It is known that the creep behavior of SiC/Al composites is strongly related to the $\mathrm{SiC}$ reinforcement; however the role of $\mathrm{SiC}$ reinforcement on the creep behavior based on the load transfer has not been understood clearly yet.

The strengthening mechanism through the load transfer from matrix to reinforcement in composite materials has been formulated by the shear-lag model ${ }^{17-19}$ Recently, the generalized shear-lag model ${ }^{20}$ and a new concept of effective aspect ratio for misaligned cylindrical whisker were suggested to analyze the load transfer efficiency of misaligned reinforcement in metal matrix considering both the aspect ratio and misorientation 
angle. In this study, the effects of aspect ratio, misorientation, and volume fraction of $\mathrm{SiC}$ reinforcement on creep resistance of $\mathrm{SiC} / 2124 \mathrm{Al}$ composites is discussed related to the load transfer efficiency of $\mathrm{SiC}$ reinforcement based on the generalized shear-lag model.

\section{EXPERIMENTAL PROCEDURES}

The SiCp/2124Al and SiCw/2124Al MMCs were fabricated by the PM process using atomized $2124 \mathrm{Al}$ powders with average diameter of $20 \mu \mathrm{m}$ and $\alpha-\mathrm{SiC}$ particles with average diameter of $8 \mu \mathrm{m}$ or $\beta-\mathrm{SiC}$ whiskers with average diameter of $1.5 \mu \mathrm{m}$ and average length of $50 \mu \mathrm{m}$. The $\mathrm{SiC}$ reinforcements and 2124Al powders were wet mixed in ethanol under ultrasonic stirring conditions. The mixtures were dried and consolidated into cylindrical billets by hot pressing at $570{ }^{\circ} \mathrm{C}$ with a pressure of $90 \mathrm{MPa}$ under $1 \times 10^{-5}$ Torr. The consolidated ingots of $\mathrm{SiCw} / 2124 \mathrm{Al}$ composite were hot extruded with varying extrusion ratios of 10:1, 15:1, and 25:1, while the consolidated billets of $\mathrm{SiCp} / 2124 \mathrm{Al}$ composite were hot extruded with an extrusion ratio of 25:1 at $500{ }^{\circ} \mathrm{C}$. The extruded bars were solution heat treated at $493{ }^{\circ} \mathrm{C}$ for $3 \mathrm{~h}$ followed by aging at $192{ }^{\circ} \mathrm{C}$ for $8 \mathrm{~h}$. The solid-solution heat treatment followed by aging treatment (so-called T6 heat treatments) can relax the residual stress during extrusion process and form nano-sized precipitates within matrix, which can strengthen the $2124 \mathrm{Al}$ matrix.

The aspect ratios of reinforcement were measured from the extracted $\mathrm{SiC}$ phase by selectively dissolving the $\mathrm{Al}$ matrix of $\mathrm{SiC} / 2124 \mathrm{Al}$ composite in $\mathrm{NaOH}$ solution. The distribution of misorientation angles of $\mathrm{SiC}$ whiskers in $\mathrm{SiCw} / 2124 \mathrm{Al}$ composite was measured using $\mathrm{x}$-ray pole figure of (111) peak intensity of $\beta-\mathrm{SiC}$ whiskers from sliced specimen cut perpendicular to the extrusion axis. Constant stress creep tests were conducted for $\mathrm{SiCw} / 2124 \mathrm{Al}$ and $\mathrm{SiCp} / 2124 \mathrm{Al}$ composites under applied stresses ranged from 30 to $110 \mathrm{MPa}$ at $300^{\circ} \mathrm{C}$. This creep temperature, which is $0.63 \mathrm{Tm}$ of $2124 \mathrm{Al}$ matrix, is determined by considering the actual working temperature of pistons and crank rods, which can be replaced by 2124Al matrix composites. The temperature of specimen was maintained within $\pm 0.5{ }^{\circ} \mathrm{C}$, and the dimensional change of the specimen was measured with a resolution of $\pm 5 \mu \mathrm{m}$ during the creep test.

\section{RESULTS AND DISCUSSION}

\section{A. Effect of SiC whisker alignment on creep behavior of SiCw/2124Al}

The conventional shear-lag model is based on the assumption that all whiskers are aligned parallel to the loading axis in matrix; however, in a real situation, the whiskers are quite misaligned in matrix even after hot extrusion or rolling of metal matrix composite, and those whiskers have a lower load transfer efficiency than the perfectly aligned whiskers. Recently Ryu et al. ${ }^{20}$ suggested the generalized shear-lag model, considering the effect of misorientation distribution of reinforcement on load transfer efficiency in MMCs. In the generalized shear-lag model, a new parameter defined as effective aspect ratio of each whisker was proposed as follows

$$
S_{\text {eff }}=S \cos ^{2} \theta+\left(\frac{3 \pi-4}{3 \pi}\right)\left(1+\frac{1}{S}\right) \sin ^{2} \theta,
$$

where $S$ is aspect ratio of whisker and $\theta$ is misorientation angle between the whisker axis and loading axis.

Figure 1 shows the scanning electron micrographs of extruded $\mathrm{SiCw} / 2124 \mathrm{Al}$ composites with different extrusion ratios. The average aspect ratio $S$ of $\mathrm{SiC}$ whiskers was measured from the extracted whiskers by selectively dissolving the $\mathrm{Al}$ matrix of $\mathrm{SiCw} / 2124 \mathrm{Al}$ composites in $\mathrm{NaOH}$ solution. The average aspect ratio decreased with increasing extrusion ratio due to a larger amount of deformation during extrusion as shown in Table I. At the same time, the whiskers in composites were not perfectly aligned but misaligned with various angles from the extrusion axis as shown in Fig. 1. As the $\beta-\mathrm{SiC}$ whiskers are single-crystalline phase grown along the $\langle 111\rangle$ direction, the $\mathrm{x}$-ray diffraction intensity from (111) plane of whiskers in $\mathrm{x}$-ray pole figure obtained from a specimen sliced perpendicular to the extrusion axis of $\mathrm{SiCw} /$ $2124 \mathrm{Al}$ is proportional to the density of whiskers aligned with misorientation angle $\theta$ from the extrusion axis (shown in Fig. 2). The degree of alignment of whiskers can be expressed as an exponential function, which is defined as a probability density function of misorientation distribution ${ }^{20}$

$$
\mathrm{F}(\theta)=\operatorname{Aexp}(-\mathrm{K} \theta),
$$

where $F(\theta)$ is probability density function of whiskers, which shows the fractions of whiskers aligned between misorientaion angle of $\theta$ and $\theta+\mathrm{d} \theta$, A is a preexponential constant, $\mathrm{K}$ is a constant dependent on degree of alignments, and $\theta$ is the misorientation angle. The measured degrees of alignment of $\mathrm{SiC}$ whiskers in $\mathrm{SiCw} /$ 2124Al extruded with different ratios are compared in Table I. The whiskers tend to be aligned more parallel to the extrusion axis with increasing the extrusion ratio of $\mathrm{SiCw} / 2124 \mathrm{Al}$ composite. The average effective aspect ratios can be calculated for $\mathrm{SiCw} / 2124 \mathrm{Al}$ composites using the effective aspect ratio of each whiskers at Eq. (1), which is derived from generalized shear-lag model, and probability density function of misorientation distributions as follows, ${ }^{20}$ when the loading direction is same as extrusion direction

$$
S_{\text {eff }}=\int_{0}^{\pi / 2} S_{\text {eff }}(\theta) F(\theta)(2 \pi \sin \theta) \mathrm{d} \theta,
$$

where $S_{\text {eff }}$ is average effective aspect ratio, $S_{\text {eff }}(\theta)$ is effective aspect ratio of each whisker, and $F(\theta)$ is probability 


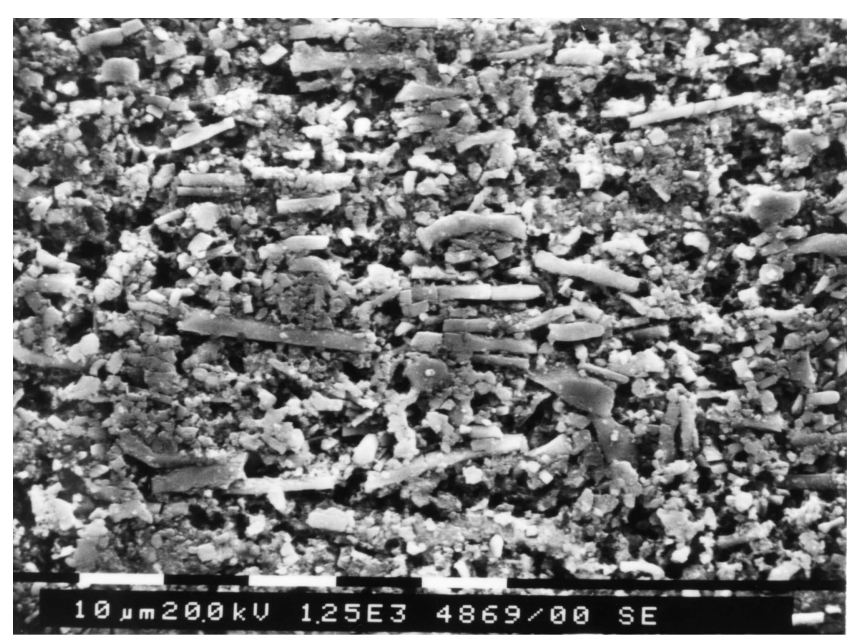

(a)

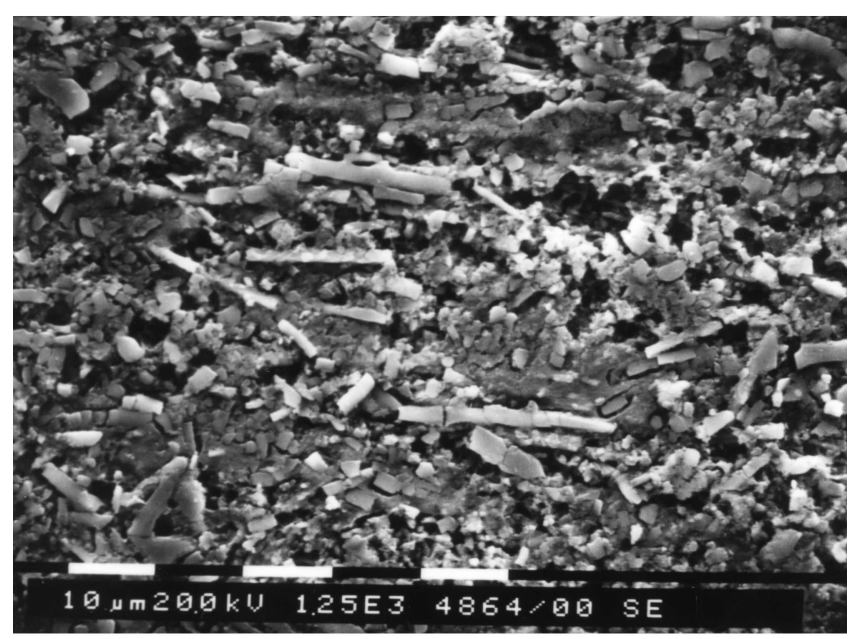

(b)

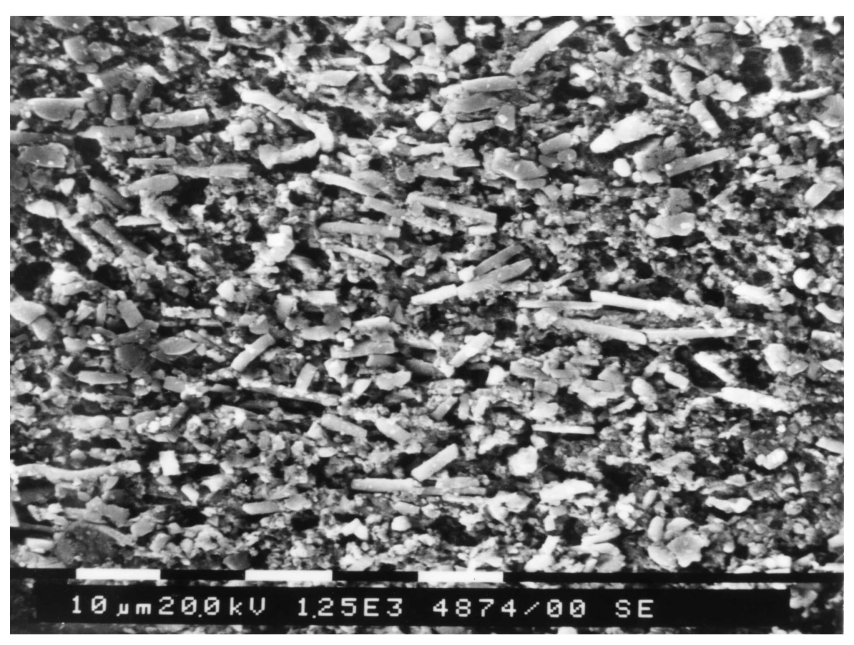

(c)

FIG. 1. Scanning electron micrographs showing the dimension and alignment of $\mathrm{SiC}$ whiskers in extruded $20 \mathrm{vol} \% \mathrm{SiCw} / 2124 \mathrm{Al} \mathrm{com}-$ posites with different extrusion ratio of (a) 10:1, (b) 15:1, and (c) 25:1.
TABLE I. Comparison of average aspect ratio $S$, degree of alignment $K$, and effective aspect ratio $S_{\text {eff }}$, measured from the extruded $20 \mathrm{vol} \%$ $\mathrm{SiCw} / 2124 \mathrm{Al}$ composites with different extrusion ratio of 10:1, 15:1, and $25: 1$.

\begin{tabular}{cccc}
\hline $\begin{array}{c}\text { Extrusion } \\
\text { ratio }\end{array}$ & $S$ & $K$ & $S_{\text {eff }}$ \\
\hline $10: 1$ & 4.4 & 2.8 & 3.1 \\
$15: 1$ & 4.2 & 4.6 & 3.6 \\
$25: 1$ & 3.6 & 4.9 & 2.8 \\
\hline \hline
\end{tabular}

density function of misorientation distribution. The average aspect ratio decreased with increasing the extrusion ratio due to an increased damage of whiskers at higher extrusion ratios, while the effective aspect ratio showed a maximum value at an extrusion ratio of 15:1 due to a contribution of whisker alignment in addition to the influence of average aspect ratio, as listed in Table I.

The variation of minimum creep rates of $\mathrm{SiCw} / 2124 \mathrm{Al}$ composites and PM processed 2124Al alloy with varying the applied stress is shown in Fig. 3(a). The SiCw/ 2124Al composites showed much higher creep resistance than that of the P/M 2124Al alloy. The SiCw/2124Al composites extruded with 15:1 showed the lowest minimum creep rate indicating the highest creep resistance. The minimum creep rates of PM 2124Al alloy and SiCw/ $2124 \mathrm{Al}$ composites followed the power-law creep behavior since the plot of minimum creep rates with respect to applied stress resulted in straight lines as shown in Fig. 3(a). The stress exponents of $\mathrm{SiC} / 2124 \mathrm{Al}$ and $\mathrm{P} / \mathrm{M}$ $2124 \mathrm{Al}$ alloy were measured as similar values of about 10. It is known that the Al alloys fabricated by ingot metallurgy process generally show stress exponents of $3-5$, whereas the $\mathrm{Al}$ alloys fabricated by powder metallurgy process showed higher stress exponents and activation energies for creep similar to those of oxide dispersion strengthened (ODS) alloys. ${ }^{22}$ The higher stress exponents of powder metallurgy processed $\mathrm{Al}$ alloys are attributed to the threshold stresses resulting from the presence of fine oxide particles. The similar stress exponents for creep of PM 2124Al alloys and SiCw/2124Al composites indicate that the controlling creep mechanism for both PM 2124Al alloys and $\mathrm{SiCw} / 2124 \mathrm{Al}$ composites could be similar, although the creep resistance of $\mathrm{SiCw} /$ $2124 \mathrm{Al}$ composites is much higher than that of PM 2124Al alloys.

Regarding the creep of metal matrix composites containing ceramic reinforcement, it is reasonably assumed that the deformation takes place in creeping matrix, and non-creeping reinforcement improves the creep resistance by reducing the effective stress on the matrix through the load transfer from matrix to reinforcement. ${ }^{12,16}$ Then the creep deformation of composites is dependent on the effective stress acting on the matrix, which is lower than the applied stress on the composite. 

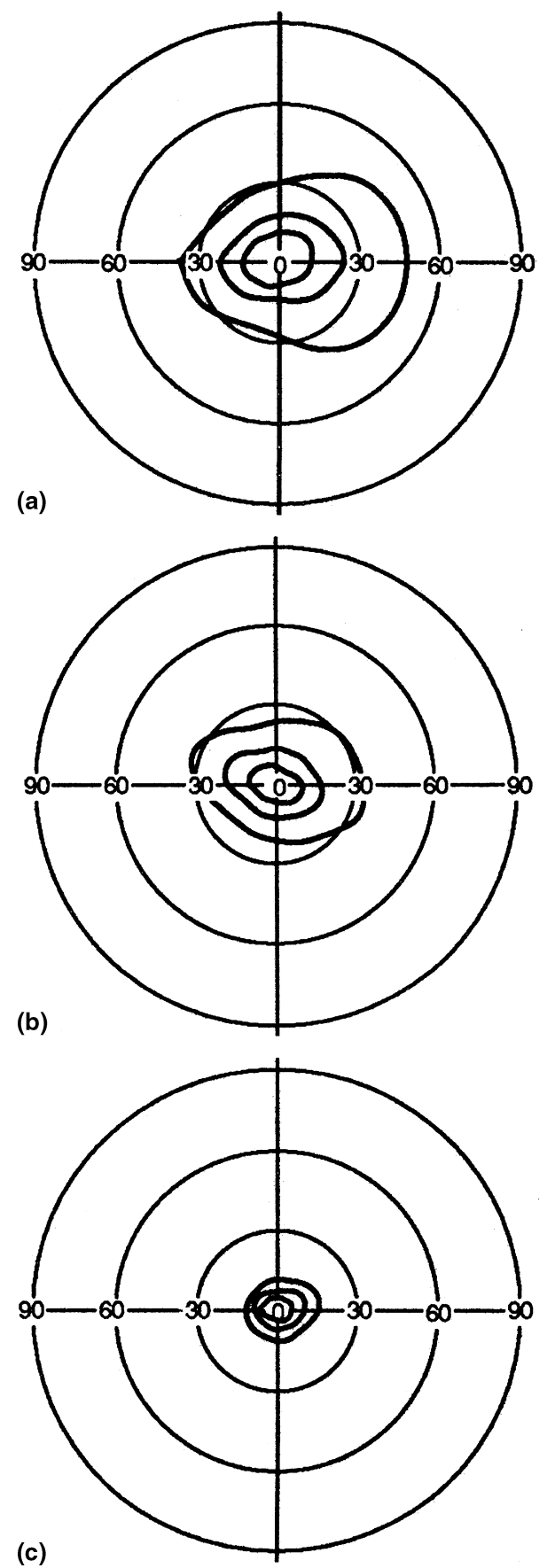

(c)

FIG. 2. X-ray pole figure of (111) peak intensity from $\mathrm{SiC}$ whiskers in sliced specimens cut perpendicular to the extrusion axis of $20 \mathrm{vol} \%$ $\mathrm{SiCw} / 2124 \mathrm{Al}$ composites extruded with different extrusion ratio of (a) 10:1, (b) 15:1, and (c) 25:1.

The ratio of the effective stress on the matrix to the applied stress on the composite in discontinuous reinforced metal matrix composites can be calculated in Eq. (4) based on the generalized shear-lag model ${ }^{20}$ as follows

$$
\frac{\sigma_{\mathrm{eff}}}{\sigma}=1-\frac{V_{\mathrm{r}}\left(S_{\mathrm{eff}} / 2+1\right)}{V_{\mathrm{f}}\left(S_{\mathrm{eff}} / 2+1\right)+V_{\mathrm{m}}}
$$
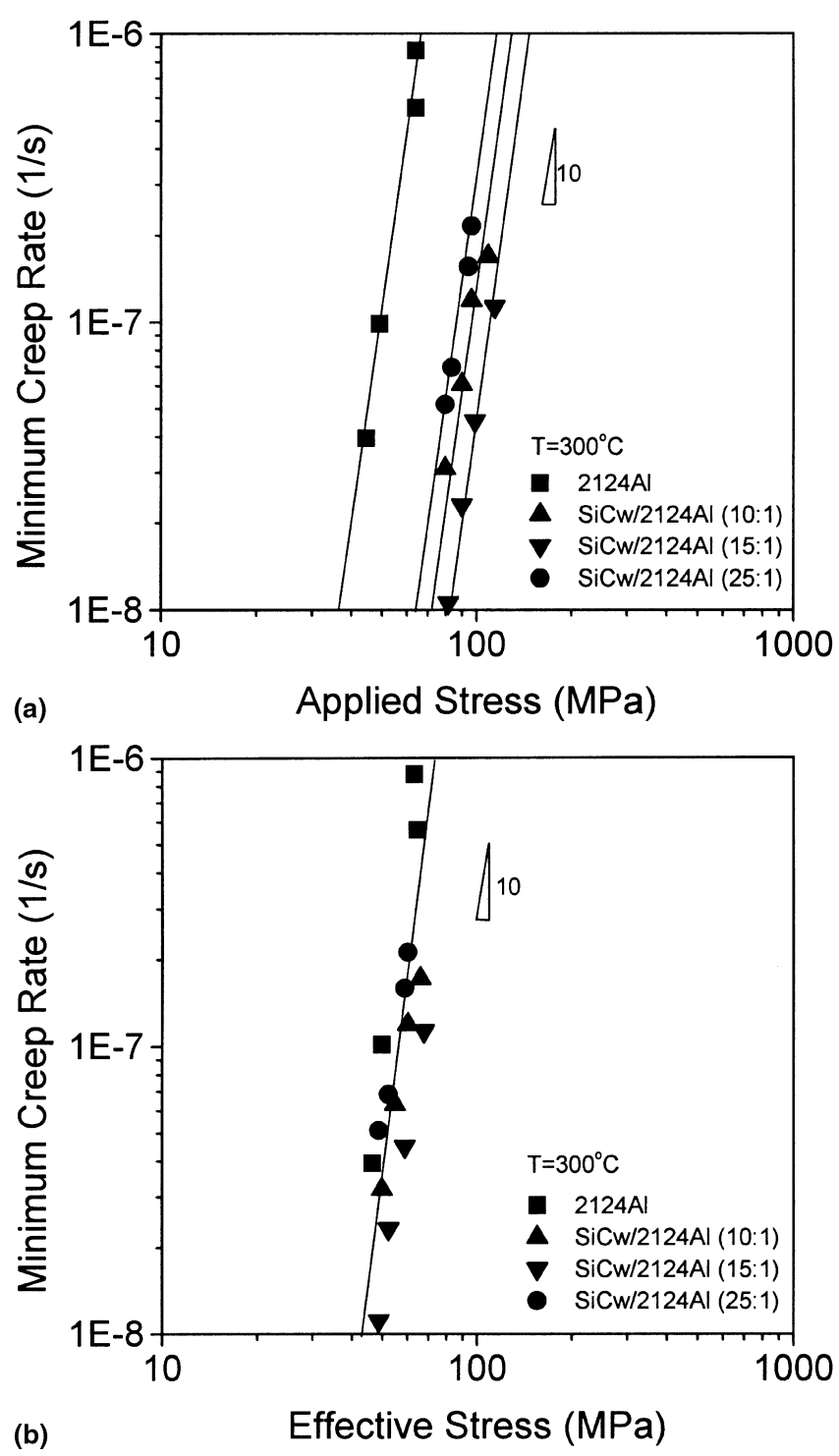

FIG. 3. Variation of minimum creep rate of $20 \mathrm{vol} \% \mathrm{SiCw} / 2124 \mathrm{Al}$ composites extruded with extrusion ratios of 10:1, 15:1 and 25:1 (a) with varying the applied stress on the composite and (b) with varying the effective stress on the matrix.

where $\sigma$ is applied stress, $V_{\mathrm{f}}$ and $V_{\mathrm{m}}$ are volume fractions of reinforcement and matrix, respectively, and $S_{\text {eff }}$ is effective aspect ratio of reinforcement. Figure 3(b) shows the variation of the minimum creep rate with varying the effective stress on the matrix calculated from the generalized shear-lag model, which is re-plotted using the creep data shown in Fig. 3(a). It is noteworthy that the minimum creep rates of $2124 \mathrm{Al}$ alloy and $\mathrm{SiCw} / 2124 \mathrm{Al}$ composites extruded with different ratios were found to be almost similar under the same effective stress. These results clearly show that the creep behavior is not dependent on the applied stress on the composites but on the effective stress on the matrix. 


\section{B. Effect of SiC particle volume fraction on creep behavior of SiCp/2124Al}

The microstructures of $\mathrm{SiCp} / 2124 \mathrm{Al}$ composites with different volume fractions of $\mathrm{SiC}$ particulate reinforcement show that the $\mathrm{SiC}$ particles are homogeneously distributed in $\mathrm{Al}$ matrix as shown in Fig. 4. The variation of
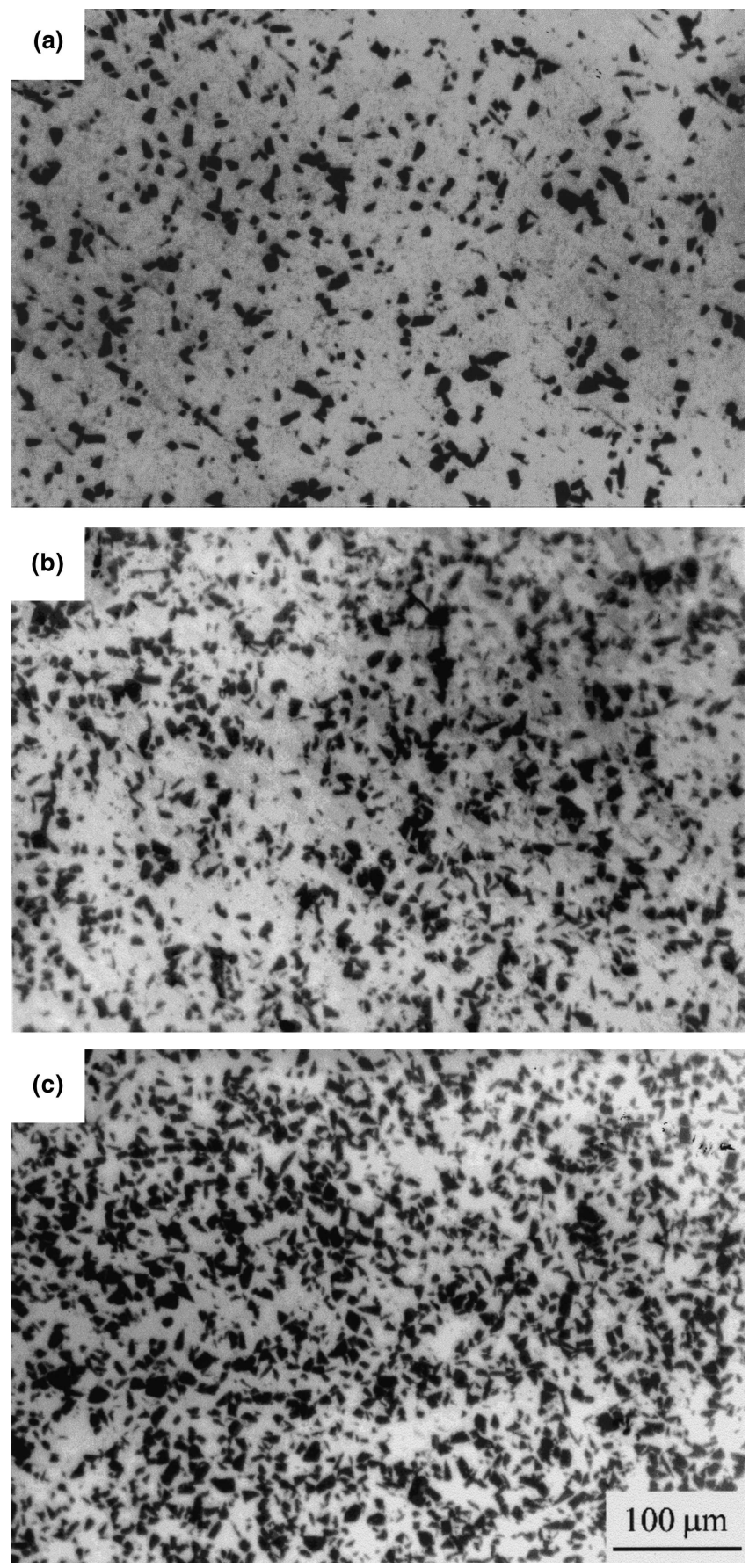

FIG. 4. Microstructures of $\mathrm{SiCp} / \mathrm{Al}$ metal matrix composites containing different volume fraction of $\mathrm{SiC}$ particles: (a) $10 \mathrm{vol} \% \mathrm{SiCp} /$ $2124 \mathrm{Al}$, (b) 20 vol\% SiCp/2124Al, and (c) 30 vol\% SiCp/2124Al. minimum creep rate with varying the applied stress on $\mathrm{SiCp} / 2124 \mathrm{Al}$ composites with different volume fractions of $\mathrm{SiC}$ particles is shown in Fig. 5(a). It is apparent that the creep resistance of the composites increases with increasing the volume fraction of $\mathrm{SiC}$ reinforcement. The $\mathrm{SiCp} / 2124 \mathrm{Al}$ composite shows apparent stress exponent of about 10, which is similar to those of $\mathrm{SiCw} / 2124 \mathrm{Al}$. The similar stress exponents for creep deformation of $\mathrm{SiCp} / \mathrm{Al}$ composites with different volume fractions indicate that the controlling creep mechanism is identical for $\mathrm{SiCp} / 2124 \mathrm{Al}$ composites with different $\mathrm{SiCp}$ volume fraction, although the creep resistance is sensitively dependent on the volume fraction of $\mathrm{SiC}$ particles. The load transfer in particle-reinforced metal matrix composite also can be analyzed using the generalized shear-lag
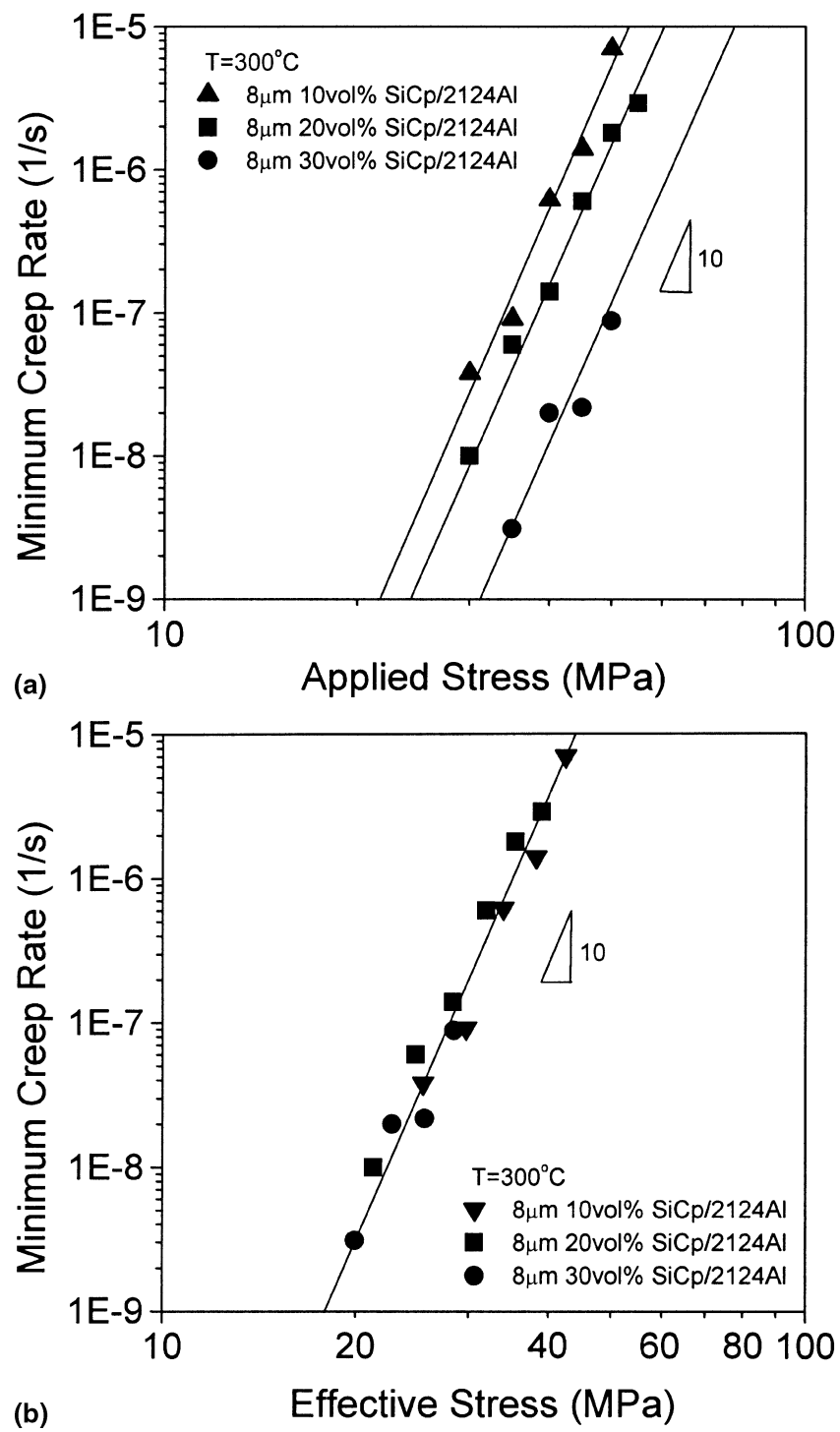

FIG. 5. The variation of minimum creep rate of $\mathrm{SiCp} / 2124 \mathrm{Al}$ composites with different volume fractions of $\mathrm{SiC}$ particles at $300{ }^{\circ} \mathrm{C}$ (a) with varying the applied stress on the composite, and (b) with varying the effective stress on the matrix. 
model and concept of effective aspect ratio as in the Appendix. As a result, the effective aspect ratio $S_{\text {eff }}$ of spherical $\mathrm{SiC}$ particle is calculated as 1.25. Then the effective stresses on matrix can be calculated using Eq. (4) where $S_{\text {eff }}$ is constant as 1.25 . The effective stresses on the matrix were calculated for $\mathrm{SiCp} / 2124 \mathrm{Al}$ composites containing 10, 20, and $30 \mathrm{vol} . \%$ of $\mathrm{SiC}$ particles based on the generalized shear-lag model. Figure 5(b) shows the variation of minimum creep rates with varying the effective stress on the matrix, which is re-plotted using the creep data shown in Fig. 5(a). The minimum creep rates $\mathrm{SiCp} / 2124 \mathrm{Al}$ composites containing different volume fraction of $\mathrm{SiC}$ particles were found to be similar under the same effective stress. The effective stress on 2124Al matrix of SiCp/Al composites is influenced by the load transfer efficiency of reinforcement, which is dependent on the volume fraction of $\mathrm{SiC}$ particles.

\section{Phenomenological creep equation for SiC/Al composites}

Figure 6 shows that the minimum creep rates of 2124Al alloy and $\mathrm{SiCw} / 2124 \mathrm{Al}$ and $\mathrm{SiCp} / 2124 \mathrm{Al}$ composites are very similar under an identical effective stress and can be fitted into a single line when plotted with varying effective stress on the matrix. These results strongly represent that the creep behavior is not dependent on the applied stress on the composite, but dependent on the effective stress on the matrix. Therefore, the conventional power-law creep equation ${ }^{21}$ for $\mathrm{SiC} / \mathrm{Al}$ composite expressed as a function of applied stress $\sigma$ needs to be modified as a function of effective stress $\sigma_{\text {eff }}$ as follows

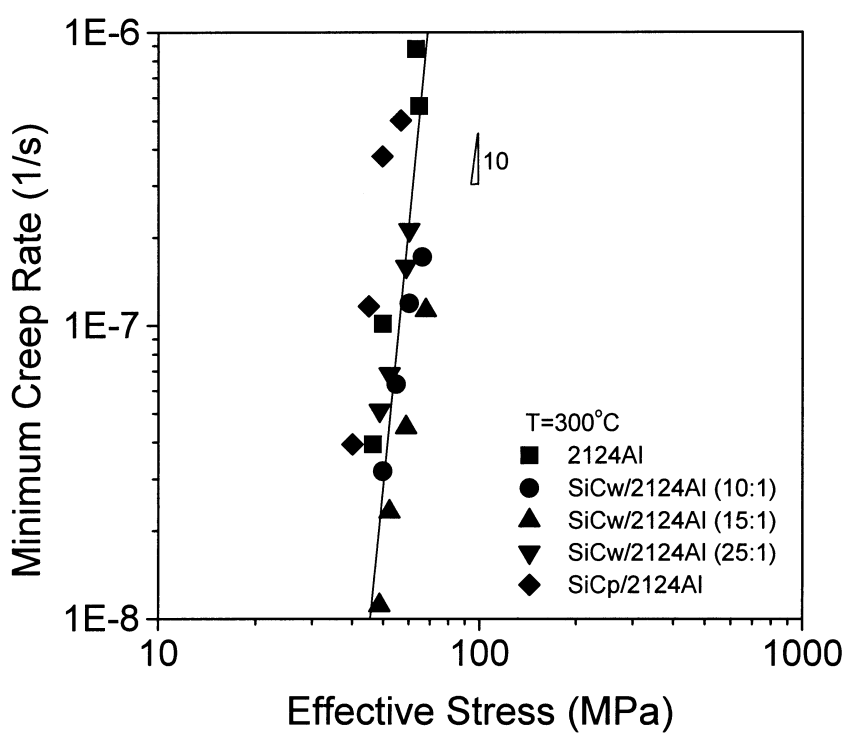

FIG. 6. The variation of minimum creep rate with varying the effective stress on the matrix of $20 \mathrm{vol} \% \mathrm{SiCw} / 2124 \mathrm{Al}$ and $20 \mathrm{vol} \% \mathrm{SiCp} /$ 2124Al composites at $300{ }^{\circ} \mathrm{C}$.

$$
\begin{aligned}
& \frac{\dot{\epsilon}}{D}=\mathrm{A} \frac{G \mathrm{~b}}{\mathrm{kT}}\left(\frac{\theta_{\text {eff }}}{G}\right)^{n} \\
& \frac{\dot{\epsilon}}{D}=\mathrm{A} \frac{G \mathrm{~b}}{\mathrm{k} T}\left[\left\{1-\frac{V_{\mathrm{f}}\left(S_{\text {eff }} / 2+1\right)}{V_{\mathrm{f}}\left(S_{\text {eff }} / 2+1\right)+1}\right\} \frac{\sigma}{G}\right]^{n},
\end{aligned}
$$

where $\dot{\epsilon}$ is minimum creep rate, $D$ is diffusivity, A is constant, $G$ is shear modulus, b is Burgers vector, $n$ is apparent stress exponent, $\mathrm{k}$ is Boltzmann's constant, and $T$ is absolute temperature. The minimum creep rates of metal matrix composites can be formulated as a function of the applied stress on the composite $\sigma$ and the effective aspect ratio $S_{\text {eff }}$ for a given volume fraction $V_{\mathrm{f}}$ of $\mathrm{SiC}$ reinforcement, which is suggested as a modified phenomenological creep equation as expressed in Eq. (5).

The effective stress on 2124Al matrix is influenced by the load transfer efficiency of $\mathrm{SiC}$ reinforcement in $\mathrm{SiC} /$ $2124 \mathrm{Al}$ composite. The load transfer efficiency of reinforcement can be represented as a function of a new parameter proposed as the effective aspect ratio, which is dependent on the average aspect ratio and misorientation angle of reinforcement, based on the generalized shearlag model. The creep resistance of metal matrix composite is directly related to the effective aspect ratio of the reinforcement. Also, it is shown that the decrease of creep rate with increasing the $\mathrm{SiCp}$ volume fraction is induced by a decrease of the effective stress applied on $2124 \mathrm{Al}$ matrix because the load transferred to reinforcement increases with increasing the $\mathrm{SiCp}$ volume fraction. From the above analysis, it is suggested that the role of $\mathrm{SiC}$ reinforcement is to improve the creep resistance of $\mathrm{SiC} / 2124 \mathrm{Al}$ composite by reducing the effective stress for creep deformation of 2124Al matrix through the load transfer from matrix to $\mathrm{SiC}$ reinforcement.

\section{CONCLUSIONS}

The high-temperature creep behaviors of $\mathrm{SiC} / \mathrm{Al}$ composites were investigated considering the load transfer between reinforcement and matrix based on the generalized shear-lag model. The minimum creep rate of $\mathrm{SiCp} /$ 2124Al composite decreased with increasing volume fraction of $\mathrm{SiC}$ particles. The $\mathrm{SiCw} / 2124 \mathrm{Al}$ composites showed the lowest minimum creep rate when extruded by $15: 1$ due to the largest effective aspect ratio of reinforcement. The minimum creep rates of $\mathrm{SiC} / 2124 \mathrm{Al}$ composites with different volume fraction and extrusion ratios were found to be similar under an identical effective stress on the matrix, which is calculated by the generalized shear-lag model. The subgrain size in the matrix was dependent on the effective stress on the matrix instead of the applied stress on the composite. The minimum creep rates of metal matrix composites could be estimated by a modified phenomenological creep equation formulated as a function of the effective on the matrix. It is suggested that the creep deformation of $\mathrm{SiCw} /$ 
2124Al composite proceeds by the deformation of $2124 \mathrm{Al}$ matrix and the role of $\mathrm{SiC}$ reinforcement is to increase the creep resistance by reducing the effective stress acting on the matrix.

\section{REFERENCES}

1. Y. Li and T.G. Langdon: Creep behavior of an AZ91 magnesium alloy reinforced with alumina fibers. Metall. Mater. Trans. A 30A, 2059 (1999).

2. T. Morimoto, T. Yamaoka, H. Lilholt, and M. Taya: Second stage creep of $\mathrm{SiC}$ whisker/6061 aluminum composite at 573K. J. Eng. Mater. Technol. 110, 70 (1988).

3. T.G. Nieh: Creep rupture of a silicon carbide reinforced aluminum composite. Metall. Trans. A 15A, 139 (1984).

4. R.S. Mishira and A.B. Pandey: Some observations on the hightemperature creep behavior of $6061 \mathrm{Al}-\mathrm{SiC}$ composites. Metall. Trans. A 21A, 2089 (1990).

5. Y. Li and T.G. Langdon: An examination of a substructureinvariant model for the creep of metal matrix composites. Mater. Sci. Eng. A 265, 276 (1999).

6. J.C. Gibeling and W.D. Nix: The description of elevated temperature deformation in terms of threshold stresses and back stresses: A review. Mater. Sci. Eng. 45, 123 (1980).

7. Y. Li and T.G. Langdon: A unified interpretation of threshold stresses in the creep and high strain rate superplasticity of metal matrix composites. Acta Mater. 47, 3395 (1999).

8. G. Gonzalez-Doncel and O.D. Sherby: High temperature creep behavior of metal matrix aluminum-SiC composites. Acta Metall. Mater. 41, 2797 (1993).

9. F.A. Mohamed, K.T. Park, and E.J. Lavernia: Creep behavior of discontinuous SiC Al composites. Mater. Sci. Eng. A 150, 21 (1992).

10. K.T. Park, E.J. Lavernia, and F.A. Mohamed: High temperature creep of silicon carbide particulate reinforced aluminum. Acta Metall. Mater. 38, 2149 (1990).

11. Y. Li and F.A. Mohamed: An investigation of creep behavior in an SiC-2124 Al composite. Acta Mater. 45, 4775 (1997).

12. V.C. Nardone and J.R. Strife: Analysis of the creep behavior of silicon carbide whisker reinforced 2124Al. Metall. Trans. A 18A, 109 (1987).

13. T.L. Dragone and W.D. Nix: Geometric factors affecting the internal stress distribution and high temperature creep rate of discontinuous fiber reinforced metals. Acta Metall. Mater. 38, 1941 (1990).

14. A.B. Pandey, R.S. Mishra, and Y.R. Mahajan: Steady state creep behavior of silicon carbide particulate reinforced aluminum composite. Acta Metall. Mater. 40, 2045 (1992).

15. J. Cadek, H. Oikawa, and V. Sustek: Threshold creep behaviour of discontinuous aluminium and aluminium alloy matrix composites: An overview. Mater. Sci. Eng. A 190, 9 (1995).

16. S.H. Hong and K.H. Chung: High temperature creep behavior of metal matrix composites. Key Eng. Mater. 104, 225 (1995).

17. H.L. Cox: The elasticity and strength of paper and other fibrous materials. Br. J. Appl. Phys. 3, 72 (1952).

18. V.C. Nardone and K.M. Prewo: On the strength of discontinuous silicon carbide reinforced aluminum composites. Scripta Metall. Mater. 20, 43 (1986).

19. V.C. Nardone: Assessment of models used to predict the strength of discontinuous silicon carbide reinforced aluminum composites. Scripta Metall. Mater. 21, 1313 (1987).

20. H.J. Ryu, S.I. Cha, and S.H. Hong: Generalized shear-lag model for load transfer in SiC/Al metal matrix composites. J. Mater. Res. 18, 2851 (2003).
21. S.L. Robinson and O.D. Sherby: Mechanical behavior of polycrystalline tungsten at elevated temperature. Acta Metall. 17, 109 (1969).

22. F.R.N. Nabarro and H.L. Villiers: The Physics of Creep (Taylor \& Francis, London, U.K., 1995).

\section{APPENDIX: EFFECTIVE ASPECT RATIO OF PARTICLE REINFORCED METAL MATRIX COMPOSITE}

Figure A1 shows the stresses acting on a spherical particulate reinforcement in a metal matrix composite. Considering the force equilibrium on a thin slice cut perpendicular to the loading axis of a spherical particle (Fig. A1), the differential normal stress $d \sigma_{\mathrm{p}}$ should balance with the shear stress $\tau_{i}$, on the circumferential surface of the thin slice. A differential equation based on the force equilibrium between the normal stress and the shear stress is derived as Eq. (A1) and can be simplified as shown in Eq. (A2)

$$
\begin{aligned}
-\mathrm{d} \sigma_{\mathrm{p}} \pi r^{2} \cos ^{2} \phi & =2 \pi r \cos \phi r \mathrm{~d} \phi \cdot \tau_{\mathrm{i}} \cos ^{2} \phi, \\
-\mathrm{d} \sigma_{\mathrm{p}} & =2 \cos \phi \cdot \tau_{\mathrm{i}} \cdot \mathrm{d} \phi,
\end{aligned}
$$

where $\sigma_{\mathrm{p}}$ is normal stress on the particle and $\tau_{\mathrm{i}}$ is shear stress at the interface between the particle and matrix. When the stress transferred from the matrix to the particle is $\sigma_{\mathrm{m}}$, the normal stress perpendicular to the thin slice $\sigma_{\mathrm{p}}$ can be calculated by integrating Eq. (A2) with a boundary condition of $\sigma_{\mathrm{p}}=\sigma_{\mathrm{m}}$ at $\phi=90^{\circ}$ as shown in Eq. (A3)

$$
\sigma_{\mathrm{p}}=\sigma_{\mathrm{m}}+(1-\sin \phi) 2 \tau_{\mathrm{i}}
$$

Then, the average normal stress on a spherical particle is calculated as the following equation:

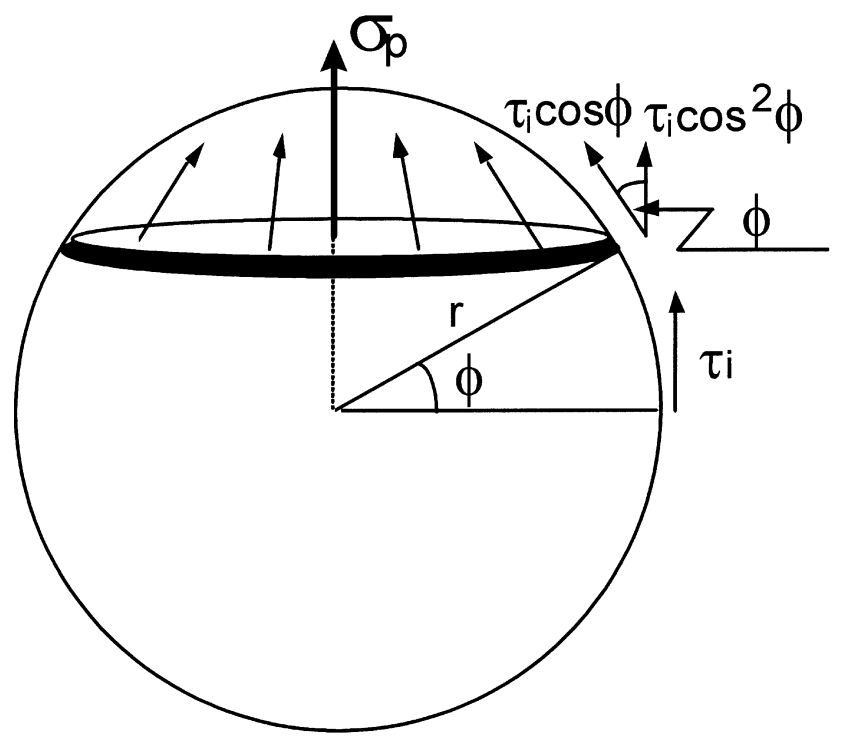

FIG. A1. Schematic diagram showing the stress components acting on a spherical particle in metal matrix composite. 


$$
\begin{aligned}
\bar{\sigma}_{\mathrm{p}} & =\frac{\int_{0}^{90} \sigma_{\mathrm{p}} \pi r^{2} \cos ^{2} \phi \cdot r \cos \phi \mathrm{d} \phi}{\int_{0}^{90} \pi r^{2} \cos ^{2} \phi \cdot r \cos \phi \mathrm{d} \phi} \\
& =\sigma_{\mathrm{m}}+\frac{5}{4} \tau_{\mathrm{i}} .
\end{aligned}
$$

Assuming the shear stress on interface is one half of the tensile stress on matrix, i.e., $\tau_{\mathrm{I}}=\sigma_{\mathrm{m}} / 2$, and the strength of a particle reinforced composite is estimated by the rule of mixture of the average normal stress on a particle, $\bar{\sigma}_{\mathrm{p}}$, and the stress on matrix $\sigma_{\mathrm{m}}$, expressed as Eq. (A5)

$$
\begin{aligned}
\sigma_{\mathrm{p}} & =V_{\mathrm{p}} \cdot\left(\sigma_{\mathrm{m}}+\frac{5}{4} \tau_{\mathrm{m}}\right)+V_{\mathrm{m}} \sigma_{\mathrm{m}} \\
& =V_{\mathrm{p}} \sigma_{\mathrm{m}}\left(\frac{1.25}{2}\right)+\sigma_{\mathrm{m}} \\
& =V_{\mathrm{p}} \sigma_{\mathrm{m}}\left(\frac{S_{\text {eff }}}{2}+1\right) .
\end{aligned}
$$

By comparing Eq. (A5) with the shear-lag model, ${ }^{12}$ the effective aspect ratio of a spherical particle is obtained as of 1.25, which is independent on the direction of loading axis due to the symmetry of a spherical particle. 